\title{
The Impact of Sleep on Female Sexuality
}

I.Y.Abdallah, M.A.Ibrahim and A.T.Taha

Dermatology,Venereology\&Andrology Dept., Faculty of Medicine, Benha Univ., Benha, Egypt

E-Mail: ayat.taha.abdelrahman@gmail.com

\begin{abstract}
Sleep is a biological requirement for human life, alongside food, water, and air. It has a vital effect on brain functions and many body systems as a result Poor sleep quality has been related to sexual difficulties.Evaluate the relationship between sleep and its effect on the sexual relationship in married women. aself-report questionnaire designed by the authors designed according to Younis et al (2017). Other questions were added to suit the purpose of study. The aim of the study and the details of the questionnaire were explained to the women before taking their informed consent. Participants were 300 women recruited from those attending Benha teaching hospital, Maternal and Childhood care units in Benha city, during the period from July to December 2020. Results: Adequate sleep duration leads to good sexual function.
\end{abstract}

Keywords: Sleep, Female sexual function.

\section{Introduction}

Sleep and sexual health have a complicated interplay. For many, sleep and sex are crucial for physical, emotional, and mental well-being. Poor sleep quality is linked to a myriad of ailments from coronary artery disease to major depressive disorders [1].

Sleep has a vital effect on brain functions and many body systems. Studies on sleep regulation suggest that two distinct and separately regulated processes may exist: the homeostatic sleep-wake process $\mathrm{S}$ and the circadian process $\mathrm{C}$ controlled by the circadian pacemaker [2].

There are multiple contributors to poor sleep, including work status/conditions, mental/physical health, and personal/socio-demographic factors. These factors, relationship processes are increasingly appreciated as major contributors to sleep duration and quality [3].

Poor sleep quality has been related to sexual difficulties. Case studies suggest that chronic insomnias sometimes increase sexual desire and arousal [4].

Other studies have shown that poor sleep quality is related to sexual problems, including sexual desire, orgasm, and arousal domains [5].

Satisfying sex is a critical element for overall health and happiness for many individuals, as sexuality plays a considerable role in intimate relationships and is an important aspect of overall emotional and physical health [6].

Several large-scale epidemiologic investigations have demonstrated significant associations between selfreported sleep duration and cardiovascular health. Specifically, both habitually short sleep durations (typically $<6$ hours) and long sleep duration ( $\geq 9$ hours) are associated with increased risk for hypertension, obesity, metabolic risk factors, coronary heart disease, and mortality [7].

\section{Material and methods}

The current study was a cross-sectional study performed on 300 married women. It started after obtaining the approval from the Department of dermatology and Andrology and the research ethics committee in Benha Faculty of Medicine.
The tool used in this study was a questionnaire designed according to [17] Other questions were added to suit the purpose of study. This questionnaire was written in English and translated into Arabic.

The aim of the study and details of the questionnaire were explained to the women before taking their informed consent. The participants were questioned in Benha teaching hospital, Maternal and Childhood care units in Benha city, during the period from July to December 2020.

\subsection{Statistical Analysis}

Data were fed to the computer and analyzed using IBM SPSS software package version 20.0. (Armonk, NY: IBM Corp) Qualitative data were described using number and percent.

\section{Results and discussion}

Sleep and sexual health have a complicated interplay. For many, sleep and sex are crucial for physical, emotional, and mental well-being. Poor sleep quality is linked to a myriad of ailments from coronary artery disease to major depressive disorders [8].

Most of the participants in our study had high degree of education (52.0\%). Education may enable them to express themselves freely and more accurately. [9].

Regarding sexual activity, our study showed that $53 \%$ of participants were sexually satisfied with good sleep duration; the results were supported by [10]; as their analyses revealed the importance of sleep duration in healthy sexual desire and genital response.

As regards sleeping habits; our participants showed some variability; $63 \%$ of the participants never took any medications to help them sleep which reflects that most of our sample participants were having normal sleeping habits; deficient androgen levels mediate the impact of insufficient core sleep on sexual response as suggested by [11]. 
Table (1) Relation between sexual activity and overall sleep quality rating $(n=300)$.

\begin{tabular}{|c|c|c|c|c|c|c|c|c|c|c|}
\hline & \multicolumn{8}{|c|}{ Overall sleep quality rating } & \multirow{3}{*}{$\chi^{2}$} & \multirow{3}{*}{$\mathbf{p}$} \\
\hline & \multicolumn{2}{|c|}{$\begin{array}{l}\text { Very good } \\
(\mathbf{n}=\mathbf{1 2 0})\end{array}$} & \multicolumn{2}{|c|}{$\begin{array}{l}\text { Fairly good } \\
(\mathbf{n}=115)\end{array}$} & \multicolumn{2}{|c|}{$\begin{array}{c}\text { Fairly bad } \\
(n=40)\end{array}$} & \multicolumn{2}{|c|}{$\begin{array}{l}\text { Very bad } \\
(\mathbf{n}=25)\end{array}$} & & \\
\hline & $\mathbf{n}$ & $\%$ & $\mathbf{n}$ & $\%$ & $\mathbf{n}$ & $\%$ & $\mathbf{n}$ & $\%$ & & \\
\hline \multicolumn{11}{|l|}{ Frequency of sexual intercourse } \\
\hline Daily & 11 & 9.2 & 7 & 6.1 & 6 & 15.0 & 0 & 0.0 & \multirow{5}{*}{$66.450^{*}$} & \multirow{5}{*}{$\begin{array}{l}\mathrm{MC}_{\mathrm{p}} \\
<0.001\end{array}$} \\
\hline 2-3 times a week & 72 & 60.0 & 68 & 59.1 & 8 & 20.0 & 5 & 20.0 & & \\
\hline Once a week & 26 & 21.7 & 25 & 21.7 & 12 & 30.0 & 4 & 16.0 & & \\
\hline Once a month & 6 & 5.0 & 9 & 7.8 & 13 & 32.5 & 6 & 24.0 & & \\
\hline Less than that & 5 & 4.2 & 6 & 5.2 & 1 & 2.5 & 10 & 40.0 & & \\
\hline \multicolumn{11}{|l|}{ Feeling vaginal lubrication } \\
\hline Always & 63 & 52.5 & 38 & 33.0 & 10 & 25.0 & 12 & 48.0 & \multirow{4}{*}{$37.175^{*}$} & \multirow{4}{*}{$<0.001^{*}$} \\
\hline $\begin{array}{l}\text { About half the times of sexual } \\
\text { encounters }\end{array}$ & 18 & 15.0 & 48 & 41.7 & 12 & 30.0 & 2 & 8.0 & & \\
\hline $\begin{array}{l}\text { Less than half the times of sexual } \\
\text { encounters }\end{array}$ & 19 & 15.8 & 18 & 15.7 & 12 & 30.0 & 4 & 16.0 & & \\
\hline Rarely & 20 & 16.7 & 11 & 9.6 & 6 & 15.0 & 7 & 28.0 & & \\
\hline \multicolumn{11}{|l|}{ Pain occur during intercourse } \\
\hline Always & 16 & 13.3 & 5 & 4.3 & 2 & 5.0 & 5 & 20.0 & \multirow{4}{*}{$44.009^{*}$} & \multirow{4}{*}{$<0.001$} \\
\hline $\begin{array}{l}\text { About half the times of sexual } \\
\text { encounters }\end{array}$ & 15 & 12.5 & 25 & 21.7 & 17 & 42.5 & 4 & 16.0 & & \\
\hline $\begin{array}{l}\text { Less than half the times of sexual } \\
\text { encounters }\end{array}$ & 27 & 22.5 & 53 & 46.1 & 9 & 22.5 & 7 & 28.0 & & \\
\hline Rarely & 62 & 51.7 & 32 & 27.8 & 12 & 30.0 & 9 & 36.0 & & \\
\hline \multicolumn{11}{|l|}{ Reaching orgasm } \\
\hline Always & 73 & 60.8 & 14 & 12.2 & 8 & 20.0 & 6 & 24.0 & \multirow{4}{*}{$97.081^{*}$} & \multirow{4}{*}{$<0.001^{*}$} \\
\hline $\begin{array}{l}\text { About half the times of sexual } \\
\text { encounters }\end{array}$ & 20 & 16.7 & 56 & 48.7 & 10 & 25.0 & 2 & 8.0 & & \\
\hline $\begin{array}{l}\text { Less than half the times of sexual } \\
\text { encounters }\end{array}$ & 15 & 12.5 & 30 & 26.1 & 15 & 37.5 & 6 & 24.0 & & \\
\hline Rarely & 12 & 10.0 & 15 & 13.0 & 7 & 17.5 & 11 & 44.0 & & \\
\hline \multicolumn{11}{|l|}{ Sexually satisfied } \\
\hline Satisfied more than 50 & 70 & 58.3 & 68 & 59.1 & 17 & 42.5 & 4 & 16.0 & \multirow{3}{*}{$47.233^{*}$} & \multirow{3}{*}{$<0.001^{*}$} \\
\hline Satisfied less than 50 & 39 & 32.5 & 35 & 30.4 & 14 & 35.0 & 6 & 24.0 & & \\
\hline Unsatisfied & 11 & 9.2 & 12 & 10.4 & 9 & 22.5 & 15 & 60.0 & & \\
\hline
\end{tabular}

$\mathrm{M} \chi^{2}$ : Chi square test

MC: Monte Carlo

$\mathrm{p}$ : $\mathrm{p}$ value for association between different categories

*: Statistically significant at $\mathrm{p} \leq 0.05$

Table (1) shows that there were $60.0 \%$ who were having sex 2-3 times per week have a very good overall sleep quality rating, $52.5 \%$ of participants who were always feeling vaginal lubrication have a very good overall sleep quality rating, $51.7 \%$ of participants who were rarely feeling pain during intercourse have a very good overall sleep quality rating, $60.8 \%$ of participants who were always reaching orgasm during intercourse have a very good overall sleep quality rating and $59.1 \%$ of participants who were sexually satisfied $>50 \%$ have a fairly good overall sleep quality rating.
Our results were compatible with [12] showing that $60 \%$ of women who were having sex 2-3 times per week have a very good overall sleep quality rating, $52.5 \%$ of participants who were always feeling vaginal lubrication have a very good overall sleep quality rating, $51.7 \%$ of participants who were rarely feeling pain during intercourse have a very good overall sleep quality rating, $60.8 \%$ of participants who were always reaching orgasm during intercourse have a very good overall sleep quality rating and $59.1 \%$ of participants who were sexually satisfied $50 \%$ have a good overall sleep quality rating. 
Table (2) Relation between sleep troubles and sexual satisfaction $(n=300)$.

\begin{tabular}{|c|c|c|c|c|c|c|c|c|}
\hline & \multicolumn{6}{|c|}{ Sexually satisfied } & \multirow{3}{*}{$\chi^{2}$} & \multirow{3}{*}{$\mathbf{p}$} \\
\hline & \multicolumn{2}{|c|}{$\begin{array}{l}\text { Satisfied more than } \\
50 \%(n=159) \\
\end{array}$} & \multicolumn{2}{|c|}{$\begin{array}{l}\text { Satisfied less than } \\
50 \%(n=94)\end{array}$} & \multicolumn{2}{|c|}{$\begin{array}{c}\text { Unsatisfied } \\
(n=47)\end{array}$} & & \\
\hline & $\mathbf{n}$ & $\%$ & $\mathbf{n}$ & $\%$ & $\mathbf{n}$ & $\%$ & & \\
\hline \multicolumn{9}{|c|}{$\begin{array}{l}\text { Waking up in the middle of the night } \\
\text { or early in the morning }\end{array}$} \\
\hline Not during the past month & 60 & 37.7 & 19 & 20.2 & 9 & 19.1 & \multirow{4}{*}{$18.738^{*}$} & \multirow{4}{*}{$0.005^{*}$} \\
\hline Less than once a week & 48 & 30.2 & 38 & 40.4 & 12 & 25.5 & & \\
\hline Once or twice a week & 30 & 18.9 & 28 & 29.8 & 17 & 36.2 & & \\
\hline Three or more times a week & 21 & 13.2 & 9 & 9.6 & 9 & 19.1 & & \\
\hline \multicolumn{9}{|c|}{ Having to get up to use the bathroom } \\
\hline Not during the past month & 61 & 38.4 & 26 & 27.7 & 6 & 12.8 & \multirow{4}{*}{$19.863^{*}$} & \multirow{4}{*}{$0.003^{*}$} \\
\hline Less than once a week & 48 & 30.2 & 35 & 37.2 & 12 & 25.5 & & \\
\hline Once or twice a week & 31 & 19.5 & 23 & 24.5 & 17 & 36.2 & & \\
\hline Three or more times a week & 19 & 11.9 & 10 & 10.6 & 12 & 25.5 & & \\
\hline \multicolumn{9}{|c|}{ Inability to breathe comfortably } \\
\hline Not during the past month & 76 & 47.8 & 22 & 23.4 & 9 & 19.1 & \multirow{4}{*}{$52.851^{*}$} & \multirow{4}{*}{$<0.001^{*}$} \\
\hline Less than once a week & 54 & 34.0 & 26 & 27.7 & 11 & 23.4 & & \\
\hline Once or twice a week & 17 & 10.7 & 35 & 37.2 & 12 & 25.5 & & \\
\hline Three or more times a week & 12 & 7.5 & 11 & 11.7 & 15 & 31.9 & & \\
\hline \multicolumn{9}{|l|}{ Coughing or snoring loudly } \\
\hline Not during the past month & 108 & 67.9 & 25 & 26.6 & 10 & 21.3 & \multirow{4}{*}{$120.910^{*}$} & \multirow{4}{*}{$<0.001^{*}$} \\
\hline Less than once a week & 35 & 22.0 & 29 & 30.9 & 5 & 10.6 & & \\
\hline Once or twice a week & 12 & 7.5 & 35 & 37.2 & 13 & 27.7 & & \\
\hline Three or more times a week & 4 & 2.5 & 5 & 5.3 & 19 & 40.4 & & \\
\hline \multicolumn{9}{|l|}{ Having bad dreams } \\
\hline Not during the past month & 64 & 40.3 & 48 & 51.1 & 9 & 19.1 & \multirow{5}{*}{$14.250^{*}$} & \multirow{4}{*}{$0.027^{*}$} \\
\hline Less than once a week & 63 & 39.6 & 29 & 30.9 & 23 & 48.9 & & \\
\hline Once or twice a week & 26 & 16.4 & 15 & 16.0 & 13 & 27.7 & & \\
\hline Three or more times a week & 6 & 3.8 & 2 & 2.1 & 2 & 4.3 & & \\
\hline \multicolumn{7}{|l|}{ Having pain } & & \\
\hline Not during the past month & 69 & 43.4 & 60 & 63.8 & 6 & 12.8 & \multirow{4}{*}{$41.458^{*}$} & \multirow{4}{*}{$<0.001^{*}$} \\
\hline Less than once a week & 49 & 30.8 & 12 & 12.8 & 15 & 31.9 & & \\
\hline Once or twice a week & 23 & 14.5 & 16 & 17.0 & 14 & 29.8 & & \\
\hline Three or more times a week & 18 & 11.3 & 6 & 6.4 & 12 & 25.5 & & \\
\hline
\end{tabular}

\footnotetext{
$\chi^{2}$ : Chi square test

$\mathrm{p}$ : $\mathrm{p}$ value for association between different categories

*: Statistically significant at $\mathrm{p} \leq 0.05$
}

Table (2) shows that there were $40.4 \%$ who were having troubles with waking up in the middle of night or early in the morning with the result of less than once per week were satisfied $<50 \%, 38.4 \%$ of participants who were not having troubles to get up at night to use the bathroom during the past month were satisfied $>50 \%$, $47.8 \%$ of participants who were not having troubles with breathing comfortably during the past month were satisfied $>50 \%, 67.9 \%$ of participants who were not having troubles with coughing or snoring loudly during the past month were satisfied $>50 \%, 51.1 \%$ of participants who were not having bad dreams during the past month were satisfied $<50 \%$ and $63.8 \%$ of participants who were not having general pain all over the body during the past month were satisfied $<50 \%$.
[13] Showed that females with sleep-disordered breathing had sexual problems. Equally, our results showed that $32.7 \%$ of participants had troubles with waking up in the middle of night or early in the morning, $31.7 \%$ of participants had troubles to get up during night to use the bathroom, $35.7 \%$ of participants had no troubles with breathing comfortably during the past month. On the other hand, $47.7 \%$ of participants had no troubles with coughing or snoring loudly during the past month. Additionally, $40.3 \%$ of participants had no bad dreams during the past month. Finally, $45 \%$ of participants had no general pain all over the body during the past month. Based on our findings, the potential etiological role of insomnia in female sexual dysfunction may present a largely untapped and potentially rich area for future investigation. 
Table (3) Relation between sexual dreams and Sexual arousal $(n=300)$.

\begin{tabular}{|c|c|c|c|c|c|c|}
\hline & \multicolumn{4}{|c|}{$\begin{array}{l}\text { Sexual arousal } \\
\end{array}$} & \multirow{3}{*}{$\chi^{2}$} & \multirow{3}{*}{$\mathbf{p}$} \\
\hline & \multicolumn{2}{|c|}{$\begin{array}{c}\text { Yes } \\
(n=161)\end{array}$} & \multicolumn{2}{|c|}{$\begin{array}{c}\text { No } \\
(\mathbf{n}=\mathbf{1 3 9})\end{array}$} & & \\
\hline & $\mathbf{n}$ & $\%$ & $\mathbf{n}$ & $\%$ & & \\
\hline \multicolumn{7}{|c|}{ Frequency of having sexual dreams } \\
\hline Daily & 4 & 2.5 & 2 & 1.4 & & \\
\hline 2-3 per week & 23 & 14.3 & 18 & 13.0 & & \\
\hline Once per week & 72 & 44.7 & 17 & 12.2 & $73.626^{*}$ & $<0.001^{*}$ \\
\hline Less than that & 55 & 34.2 & 48 & 34.5 & & \\
\hline Never & 7 & 4.3 & 54 & 38.8 & & \\
\hline \multicolumn{7}{|c|}{$\begin{array}{l}\text { The psychological effect of having sexual } \\
\text { dreams }\end{array}$} \\
\hline Increase in general happiness & 74 & 46.0 & 22 & 15.8 & & \\
\hline Decrease emotional satisfaction & 81 & 50.3 & 49 & 35.2 & $103.503^{*}$ & $<0.001^{*}$ \\
\hline No effect at all & 6 & 3.7 & 68 & 49.0 & & \\
\hline
\end{tabular}

\section{$\chi^{2}$ : Chi square test}

$\mathrm{p}: \mathrm{p}$ value for association between different categories

*: Statistically significant at $\mathrm{p} \leq 0.05$

Table (3) shows that there were $44.7 \%$ who were having sexual dreams once per week were sexually aroused and $50.3 \%$ of participants Who were psychologically affected by having a decreased emotional satisfaction because of sexual dreams were sexually aroused.

Sexual dreams are one kind of typical dreams described in humans. More than $70 \%$ of people have experienced sexual dreams in general population [14] There is a specific concern about sexual dreams in psychiatric patients as they have different features, for example, in schizophrenic patients, it was found that in their dreams there was less sexual contents, but more aggression and sadism [15] Sexual dreams may reflect the waking-day life, ethical concerns, and social problems. The related experience includes different people and settings, and brings various feelings, but there is no systematic measure available to date [16]

In a study conducted by [17], it was found that occurrence of sexual dreams was more common in women aged 20-29 years, in those having a university degree and in housewives. Its frequency was proportional to coital frequency and the frequency of orgasm. Their results showed that $51.3 \%$ of women experienced sexual dreams, also they found that $56.6 \%$ of the women were left sexually aroused the next day(s) suggesting that sexual dreams may be an outlet for expressing sexual fantasies and desires.

\section{Conclusion}

Our findings suggest that acute sleep disturbance may contribute to sexual complaints and reduced sexual activity; we conclude that good sleep is important for maintaining healthy sexual functioning.

\section{References}

[1] RW.Lewis,KS.Fugl-Meyer, R.Bosch, A.FuglMeyer, EO.Laumann \& A.Martin-Morales Risk factors of sexual dysfunction. J Sex Med, Vol.1, PP.35-9,2014.

[2] Garbarino S, Nobili L \& Costa G: Sleepiness and Human Impact Assessment: A Rapid Review. Int J Environ Res Public Health, Vol.55, PP.13831,2016 .

[3] WM.Troxel,DJ.Buysse,KA.Matthews,HM.Kravitz, JT.Bromberger,M.Sowers,Marital/cohabitation status and history in relation to sleep in midlife women. Sleep, Vol.33(7), PP.973-81,2010.

[4] CH.Schenck, I.Arnulf, MW.Mahowald, Sleep and sex: what can go wrong? A review of the literature on sleep related disorders and abnormal sexual behaviors and experiences. Sleep, Vol.30(6), PP.683-702,2007.

[5] A.Amasyali, E.Tastaban, SY.Amasyali, Y.Turan, E.Kazan, E.Sari, B.Erol, M.Cengiz ， H.Erol, Effects of low sleep quality on sexual function, in women with fibromyalgia. Int J Impot Res, Vol.28, PP.46-49,2016.

[6] SK.Bridges, SH.Lease, CR.Ellison, Predicting Sexual Satisfaction in Women: Implications for Counselor Education and Training. J Couns Dev, Vol.82(2), PP.158-166,2004.

[7] NT.Ayas, DP.White, WK.Al-Delaimy, JE.Manson, MJ.Stampfer, FE.Speizer, S.Patel, FB.Hu, A prospective study of self-reported sleep duration and incident diabetes in women. Diabetes Care, Vol. 26, PP.380-384,2003.

[8] RW.Lewis, KS.Fugl-Meyer, R.Bosch, A.FuglMeyer, EO.Laumann, A.Martin-Morales: Risk factors of sexual dysfunction. J Sex Med, Vol.1, PP.35-9,2014. 
[9] IB.Addis, SK.Van Den Eeden, CL.Wassel-Fyr, E.Vittinghoff, JS.Brown , DH.Thom, sexual activity and function in middle-aged and older women. Obs Gyne, Vol.107(4), PP.755-764,2006.

[10] ML.Andersen, TF.Alvarenga, R.Mazaro-Costa, HC.Hachul , S.Tufik ,The association of testosterone, sleep, and sexual function in men and women. Brain Res, Vol.1416, PP.80-104,2011

[11]DA.Kalmbach, JT.Arnedt, V.Pillai, JA.Ciesla, The impact of sleep on female sexual response and behavior: A pilot study. J Sex Med, Vol.12(5), PP.1221-1232,2015.

[12] MJ.Sateia, International Classification of Sleep Disorders-Third Edition. Chest, Vol.146(5), PP. 387-1394,2014.

[13]E.Shahar, S.Redline, T.Young, LL.Boland, CM.Baldwin, FJ.Nieto, JA.Robbins, Hormone Replacement Therapy and Sleep-disordered Breathing. Am J Respir Crit Care Med, Vol.167(9), PP.1186-1192,2003.
[14] Y.CKC,Sex dreams wet dreams, and nocturnal emissions. Dreaming, Vol.21, PP.197-212,2011.

[15]M.Zanasi, F.Calisti, G.Di Lorenzo, G.Valerio,Siracusano Oneiric activity in schizophrenia: textual analysis of dream reports. Conscious Cogn, Vol.20, PP.337-348,2011.

[16] M.SCHREDL,D.ATANASOVA,K.HÖRMANN,J T.MAURER,T.HUMMEL,BA.STUCK,

Information processing during sleep: the effect of olfactory stimuli on dream content and dream emotions. J Sleep Res, Vol.18(3), PP.285290,2009.

[17]I.Younis, SH.Abdelrahman, A.Ibrahim, S.Hasan,T.Mostafa, Sex dreams in married women: Prevalence, frequency, content, and drives. Dreaming,, Vol.27(3), PP. 251-259,2017. 